\title{
Description of the Hydrologic Engineering Center's Hydrologic Modeling System (HEC-HMS) and Application to Watershed Studies
}

HMS is a valuable tool for predicting and managing human impact on rainfall-runoff response at points of interest within a watershed. HMS results can be used directly or in conjunction with other software for studies of water availability, urban drainage, flow forecasting, future urbanization impact, reservoir spillway design, flood damage reduction, floodplain regulation, wetlands hydrology, and systems operation.

MODEL DESCRIPTION: HMS simulates the precipitation-runoff processes of dendritic watershed systems; it is applicable in a wide range of geographic areas for solving the widest possible range of problems. Hydrographs produced by HMS are used directly or in conjunction with other software for studies of water availability, urban drainage, flow forecasting, future urbanization impact, reservoir spillway design, flood damage reduction, floodplain regulation, wetlands hydrology, and systems operation.

HMS features a completely integrated work environment including a database, data entry utilities, computation engine, and results reporting tools. A graphical user interface allows the user seamless movement between the different parts of the program. Program functionality and appearance are the same across all supported platforms. Time-series, paired, and gridded data are stored in the Data Storage System HEC-DSS (http://www.hec.usace.army.mil/software/hec-dss/ hecdssvue-dssvue.htm). Storage and retrieval of data are generally transparent to the user. Precipitation and discharge gauge information can be entered manually within the program or can be loaded from previously created DSS files. Results stored by the program in the database are accessible by other HEC software. Data entry can be performed for individual basin elements such as subbasins and stream reaches or simultaneously for entire classes of similar elements. Tables and forms for entering necessary data are accessed from a visual schematic of the basin. All computations are performed in metric units. Input data and output results may be U.S. customary or metric and are automatically converted when necessary.
HEC-HMS = Hydrologic Engineering Center's Hydrologic Modeling System

HEC-HMS is a tool for watershed management that can account for human impact to determine the effect on the magnitude, quantity, and timing of runoff at points of interest.

HMS is applicable in a wide range of geographical areas for solving the widest possible range of problems.

General Descripton. When developing an HMS model, a basin model, meteorological model, and control specifications need to be defined (Figure 1). The physical representation of watersheds or basins and rivers is configured in the basin model. Hydrologic elements are connected in a dendritic network to simulate runoff processes. Available elements are: subbasin, reach, junction, reservoir, diversion source, and sink. Meteorologic data analysis is performed by the meteorologic mode and includes precipitation and evapotranspiration. The time span of a simulation is controlled by control specifications, which include a starting date and time, ending date and time, and computation time-step.

Hydrologic elements are the building blocks of a basin model. An element represents a physical process such as a watershed catchment, stream reach, or confluence. An element uses a mathematical model to describe the physical process. Sometimes the model is only a good approximation of the original physical process over a limited range of environmental conditions.

As noted above, a mathematical model consists of equations that represent the behavior of various hydrologic system components, or "methods." A "method" consists of all of the details of the equations, initial conditions, state variables, boundary conditions, and means of solving the equations. To make the program suitable for many different conditions, most elements have more than one method for approximating the physical process. For example, 
Project Name : Castro

Description: Castro Valley Urban Study

- Components

Basin Model

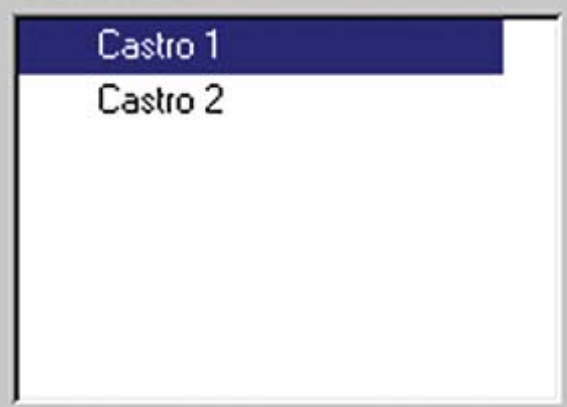

Meteorologic Model

GageWts
Control Specifications

$\operatorname{Jan} 73$

Component Description : Existing conditions

Click component for description; double click to edit.

Figure 1. Example HMS model. The name of the model is "Castro." In this HMS model there are two basin models, "Castro 1" and "Castro 2," one meteorologic model "GageWts," and one control specification, "Jan 73"

there are seven different methods for calculating the excess precipitation in a subbasin element. HMS includes the following methods:

> Precipitation methods, including an observed (historical) precipitation event, a frequency-based hypothetical precipitation event, or an event that represents the upper limit of precipitation possible at a given location.

$>$ Evapotranspiration methods compute the amount of infiltrated water that is removed back to the atmosphere through evaporation and plant use.

$>$ Loss methods estimate the amount of precipitation that infiltrates from the land surface into the soil.

$>$ Direct-runoff methods describe overland flow, storage, and energy losses as water runs off a watershed and into the stream channels.

$>$ Baseflow methods estimate the amount of infiltrated water returning to the channel.

> Hydrologic routing methods account for storage and energy flux as water moves through stream channels and water control structures.

HMS has been designed to be as flexible as possible in how the hydrologic system is defined. For ex- ample, you could choose to combine the deficit and constant rate loss method with the Clark transform method. The program will do the work of connecting the excess precipitation from the loss method to the transform method for computing surface runoff. Most methods can be successfully combined with any other method to compute watershed discharge. However, the applicability of any particular method depends on the characteristics of the watershed and some methods may not be appropriate for some hydrologic engineering studies.

Data entry, program execution, and result visualization are easy with HMS. Each of the subbasin model elements and the precipitation model have editors for selecting computation methods and entering the required parameter data. The user indicates method choices and specifies initial conditions and parameters using a graphical user interface (GUI). For example, the Green and Ampt infiltration method requires an initial loss, volume moisture deficit, wetting front suction, hydraulic conductivity, and percent impervious area. The user is responsible for collecting and analyzing the land use and soil data 
necessary to compute the parameter values. A similar approach is used for all of the other method choices included in the program. The HEC-HMS Technical Reference Manual (USACE 2000b) includes suggestions for estimating the parameters for each model included in the program.

A computation run is created by combining a basin model, meteorologic model, and control specifications. Run options include a precipitation or flow ratio, capability to save all basin states at a point in time, and ability to begin a simulation from previously saved states. Computation results are viewed from the basin model schematic. Global and element summary tables include information on peak flow and total volume. Time-series tables and graphs are available for elements. Figure 2 (Figure 7 in the Case Study Application section) shows an output graph for a subbasin element following the execution of a run.

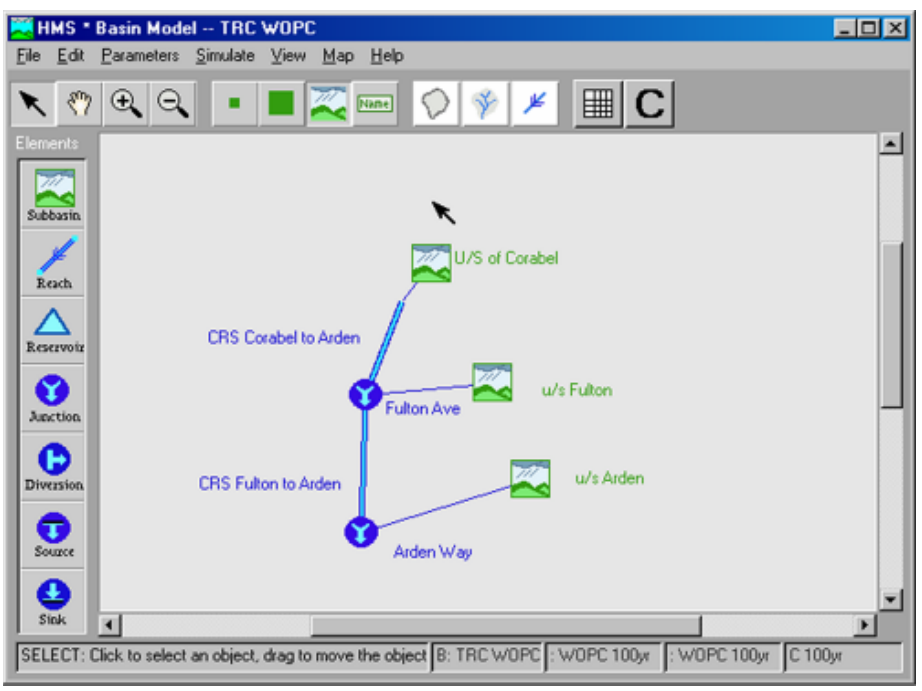

Figure 2. CRS basin schematic

Support Software. The HEC-Geospatial Hydrologic Modeling Extension (GeoHMS) is a public-domain extension to ArcView GIS and Spatial Analyst extension. ArcView GIS and its Spatial Analyst extension are available from the Environmental Systems Research Institute, Inc. (ESRI).

HEC-GeoHMS allows users to visualize spatial information, document watershed characteristics, perform spatial analysis, delineate subbasins and streams, construct inputs to hydrologic models, and assist with report preparation. Working with HECGeoHMS through its interfaces, menus, tools, buttons, and context-sensitive online help, in a Windows environment, allows the user to expediently create hydrologic inputs that can be used directly with the HEC-HMS program.
Model Development. The HEC-HMS Applications Guide (http://www.hec.usace.army.mil/software/hechms/documentation/hts_applications.pdf), lists the following steps that can be taken to obtain the desired result using the HMS program:

$>$ Identify the decision required.

> Determine what information is required to make a decision.

$>$ Determine the appropriate spatial and temporal extent of information required.

$>$ Identify methods that can provide the information, identify criteria for selecting one of the methods, and select a method.

$>$ Calibrate and verify the model.

$>$ Collect/develop boundary conditions and initial conditions appropriate for the application.

$>$ Apply the model.

$>$ Do a reality check and analyze sensitivity.

$>$ Process results to derive required information.

Calibration. HMS includes an automatic calibration tool that can be used to estimate parameter values and initial conditions for most methods, given observations of hydrometeorological conditions. Most parameters for methods included in subbasin and reach elements can be estimated automatically using the optimization manager. Observed discharge must be available for at least one element before optimization can begin. Parameters at any element upstream of the observed flow can be estimated. Six different objective functions are available to estimate the goodness-of-fit between the computed results and observed discharge. Two different search methods can be used to find the best fit between the computed results and observed discharge. Constraints can be imposed to restrict the parameter space of the search method.

\section{CASE STUDY APPLICATION/ESTIMATING IMPACTS OF URBANIZATION IN THE CRSISRS WATERSHED}

Watershed Description. The Chicken Ranch Slough and Strong Ranch Slough (CRS/SRS) watershed is an urban watershed of approximately 15 square miles within Sacramento County, in northern California. The watershed is developed primarily for residential, commercial, and public uses. The terrain in the watershed is relatively flat. The soil is primarily of sandy loam. It exhibits a high runoff potential.

Located in the headwaters of CRS is a 320-acre (0.5- square-mile) undeveloped area. As a result of increasing land values, the owners of the land are petitioning to rezone their land and develop it for new homes and businesses. In order for development to 
be allowed, the owners must mitigate for any increased runoff caused by the development.

To determine the feasibility of this project, it was necessary to know the without-development peak runoff and the with-development peak runoff for the selected event. The HMS program will use a watershed model to compute the peak flow for the different watershed conditions. Results of previous drainage studies in the area, USGS topographic and soils maps, and field investigations were used to develop the model.

The study area was defined and the study area was divided into sub-basins. The initial and constant rate runoff-volume method was used to model infiltration. Snyder's unit hydrograph direct-runoff transform method was used to model the direct-runoff transform. The Muskingum-Cunge 8-point channel routing method was used to model routing.

Model Calibration and Verification. For this case study, the following parameters were required:

$>$ Initial and constant loss rates and percent directly connected impervious area for the runoff-volume method.

$>$ Lag time and peaking coefficient for the runoff transform.

$>$ Roughness values for the channel routing method.

In addition, channel properties such as reach length, energy slope, and channel geometry need to be measured for the channel routing method. The magnitude and AEP of historical events used for calibration should be consistent with the intended application of the model. Three significant events that occurred since the installation of the gauges in the CRS/SRS watershed were considered in developing the model.

Application Summary. The goal of this case study application was to identify whether the development of an open area in the Chicken Ranch Slough watershed increased runoff, and if so, how much. Using available watershed data and computer program HEC-HMS, the analyst was able to answer the questions. The development does increase the peak runoff and total volume of runoff. If the development is to be permitted, some water control features must be included to reduce the peak for the 0.01 AEP storm from 1,003 cfs to $941 \mathrm{cfs}$.

POINTS OF CONTACT: This note was written by Mr. Matt Fleming at the Hydrologic Engineering Center, Davis, CA. For additional information, contact Mr. Fleming (530-756-1104, Matthew.J.Fleming@ hec01.usace.army.mil) or the Manager of the Systemwide Modeling Assessment and Restoration Technologies (SMART) Research Program, Dr. Steve Ashby, (601-634-2387, Steven.L. Ashby@erdc. usace.army.mil).

A more detailed version of this data can be found in ERDC/TN SMART-04-3.

This publication is intended to be used as a tool to distribute information on research being conducted under the System-wide Modeling, Assessment, and Restoration Technologies (SMART) Program. Communications are welcomed and should be addressed to the SMART Program Manager, Dr. Steven Ashby (Steven.L.Ashby@erdc. usace.army.mil), U.S. Army Engineer Research and Development Center, ATTN: CEERD-EP-P, 3909 Halls Ferry Road, Vicksburg, MS 39180-6199; telephone (601) 634-2387. The contents of this publication are not to be used for advertising, publication, or promotional purposes nor are they to be published without proper credit. Citation of trade names does not constitute an official endorsement or approval of the use of such commercial products.

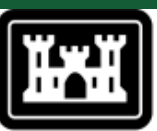

US Army Corps of Engineers ${ }^{\circledR}$ 